\title{
Structure and magnetic properties of $\mathrm{Zr}-\mathrm{Mn}$ substituted strontium hexaferrite $\operatorname{Sr}(\mathrm{Zr}, \mathrm{Mn})_{x} \mathrm{Fe}_{12-2 x} \mathrm{O}_{19}$ nanoparticles synthesized by sol-gel auto-combustion method
}

\author{
S ALAMOLHODA ${ }^{1}$, S M MIRKAZEMI ${ }^{1 * *}, Z_{\text {GHIAMI }}{ }^{2}$ and M NIYAIFAR ${ }^{3}$ \\ ${ }^{1}$ School of Metallurgy and Materials Engineering, Iran University of Science \& Technology (IUST), Narmak, \\ Tehran 13114-16846, Iran \\ ${ }^{2}$ Department of Materials Engineering, Najafabad Branch, Islamic Azad University, P.O. Box 85141-43131, Isfahan, Iran \\ ${ }^{3}$ Department of Physics, Ahvaz Branch, Islamic Azad University, 37333-61349, Ahvaz, Iran
}

MS received 19 January 2016; accepted 10 March 2016

\begin{abstract}
In this research, nano-sized powders of $\mathrm{Zr}-\mathrm{Mn}$ substituted strontium hexaferrite $\left(\operatorname{Sr}\left(\mathrm{Zr}, \mathrm{Mn}_{x} \mathrm{Fe}_{12-2 x} \mathrm{O}_{19}\right.\right.$ $(x=0,2,2.5,3))$ were synthesized by sol-gel auto-combustion route using subsequent heat treatment. The samples were characterized using X-ray diffraction (XRD), Fourier transform infrared spectroscopy (FTIR), field emission scanning electron microscope (FESEM), transmission electron microscopy (TEM), Mössbauer spectroscopy and vibration sample magnetometer (VSM) techniques. XRD and Mössbauer spectroscopy results revealed formation of $\mathrm{Sr}(\mathrm{Zr}, \mathrm{Mn})_{x} \mathrm{Fe}_{12-2 x} \mathrm{O}_{19}$ accompanied with $\mathrm{Mn}_{\delta} \mathrm{Fe}_{2-\delta} \mathrm{O}_{4}$ lateral phase in the samples. Also, FTIR and XRD results demonstrated presence of SrO impurity phase. FESEM micrographs show particle size reduction and presence of two distinct powder morphologies with different brightness levels with $\mathrm{Zr}^{4+}$ and $\mathrm{Mn}^{2+}$ substitutions which approves existence of lateral phases in the substituted samples. TEM micrographs show nanometric particles with sizes smaller than $100 \mathrm{~nm}$ with high crystallinity. Mössbauer results showed that at low level of substitution, $\mathrm{Zr}^{4+}$ ions prefer to occupy both $4 \mathrm{f} 1$ and $2 \mathrm{~b}$ however, at higher level of substitution, they prefer exclusively $4 \mathrm{f} 1$ site. While, $\mathrm{Mn}^{2+}$ ions distributed approximately equally between $12 \mathrm{k}$ and $2 \mathrm{a}$ sites. The presence of nonmagnetic $\mathrm{Zr}^{4+}$ cation leads to decrease in exchange interaction, especially at 12k and 2a sites. VSM results showed decrement of coercivity force $\left(_{i} H_{c}\right.$ ) from 5593.60 to 3282.46 Oe and maximum magnetization from 62.60 to $46.15 \mathrm{emu}^{-1}$, respectively, by increment of $\mathrm{Zr}-\mathrm{Mn}$ substitution values. Variations in maximum magnetization magnitude have been explained on the basis of occupation of the substituted cations at different iron sites.
\end{abstract}

Keywords. Strontium hexaferrite; Zr-Mn substitution; Mössbauer spectroscopy; magnetic properties.

\section{Introduction}

Strontium hexaferrite $\left(\mathrm{SrFe}_{12} \mathrm{O}_{19}\right)$ has interesting chemical, physical and magnetic properties in addition to high performance-to-cost ratio. These properties, particularly the magnetic properties, made it suitable for a wide variety of applications such as; recording media, permanent magnets, telecommunication and components in microwave, high frequency and magneto-optical devices [1-5].

Each of the mentioned applications requires special magnetic properties; hence, the magnetic properties of hexaferrite must be tuned to make it suitable for different applications. One of the ways to modify magnetic properties of hexaferrites is substitution of suitable elements in the structure [6]. For these applications, many studies on cation substitution have been carried out since intrinsic magnetic properties of strontium hexaferrite depend on the synthesis conditions, particle size and shape and the cations configuration in the magnetoplumbite crystal structure [7-10].

\footnotetext{
*Author for correspondence (mirkazemi@iust.ac.ir)
}

To achieve highly homogenous ultrafine particles, various chemical synthesis routes have been developed such as chemical co-precipitation [11], hydrothermal [12], sol-gel [13] and sol-gel auto-combustion [14]. Among these methods, solgel auto combustion is a cost effective and simple preparation route resulting in ultrafine and homogeneous powder [15].

Researchers have been replaced strontium and iron ions of strontium hexaferrite with ions of elements such as $\mathrm{Mg}-\mathrm{Zr}$ [16], Mg-Sn [17], Zn-Nb [18], Zr-Mn [19], Mn-Co-Zr [20], $\mathrm{Mn}-\mathrm{Zr}-\mathrm{Ni}$ [1], etc. Using substituted strontium hexaferrite make this material proper for applications such as microwave absorbers, electromagnetic absorbing applications and other practical applications at high frequency $[1,16,17,20]$. Some substitutions could make the material proper for perpendicular magnetic recording and high density recording media with reducing ${ }_{\mathrm{i}} H_{\mathrm{c}}$ and increasing the saturation magnetization $[18,19]$.

Up to authors' knowledge, the effect of Zr-Mn substitutions in strontium hexaferrite was not studied by Mössbauer spectroscopy. In this research, with the aim of application for microwave absorption in X-band, a series of $\mathrm{Sr}(\mathrm{Zr}, \mathrm{Mn})_{x} \mathrm{Fe}_{12-2 x} \mathrm{O}_{19}(x=0,2,2.5,3)$ are synthesized by 
sol-gel auto-combustion route and the effect of different amounts of $\mathrm{Zr}$ and $\mathrm{Mn}$ substitutions on phase constituents, microstructure, Mössbauer spectra and magnetic properties have been studied.

\section{Materials and methods}

To prepare $\mathrm{Sr}(\mathrm{Zr}, \mathrm{Mn})_{x} \mathrm{Fe}_{12-2 x} \mathrm{O}_{19}(x=0,2,2.5,3)$, proper amounts of metal nitrates: $\mathrm{Fe}\left(\mathrm{NO}_{3}\right)_{3} \cdot 9 \mathrm{H}_{2} \mathrm{O}$ (99\% Merck), $\mathrm{Sr}\left(\mathrm{NO}_{3}\right)_{2}$ (99\% Merck), $\mathrm{Mn}\left(\mathrm{NO}_{3}\right) \cdot 4 \mathrm{H}_{2} \mathrm{O}$ (99\% Merck) and $\mathrm{ZrO}\left(\mathrm{NO}_{3}\right)_{2} \cdot x \mathrm{H}_{2} \mathrm{O}$ (99\% Merck) were dissolved completely into $50 \mathrm{ml}$ distilled water to make an aqueous solution. Then, citric acid $\left(\mathrm{C}_{6} \mathrm{H}_{8} \mathrm{O}_{7}, 99 \%\right.$ Merck) was added to the above mixture as a chelating agent. The molar ratio of $\mathrm{Fe} / \mathrm{Sr}$ was fixed to 11 in different samples and the nitrate to citrate ratio was fixed to $1: 1$. The $\mathrm{pH}$ of the solution was increased to 7 by addition of ammonia solution. Then cetyl trimethyl ammonium bromide (CTAB), $\mathrm{C}_{19} \mathrm{H}_{42} \mathrm{BrN}$ (99\% Merck) was added to the solution as surfactant. The resulting sol had been heated at constant temperature of $80^{\circ} \mathrm{C}$ on magnetic stirrer to complete the reaction to form the gel precursor. Then, the dried precursor undergoes a self-ignition reaction to form a very fine brown foamy powder. Finally, the samples were calcined at $800^{\circ} \mathrm{C}$ for $1 \mathrm{~h}$. The samples were coded $x_{0}, x_{2}, x_{2.5}$, $x_{3}$ according to their $x$ values.

Phase identification of the samples has been performed by a Philips X'pert Pro X-ray diffractometer (XRD) using $\mathrm{CuK} \alpha$ radiation $(\lambda=0.1541 \mathrm{~nm})$. Lattice constants ( $a$ and $c)$ of the samples were calculated from XRD patterns by
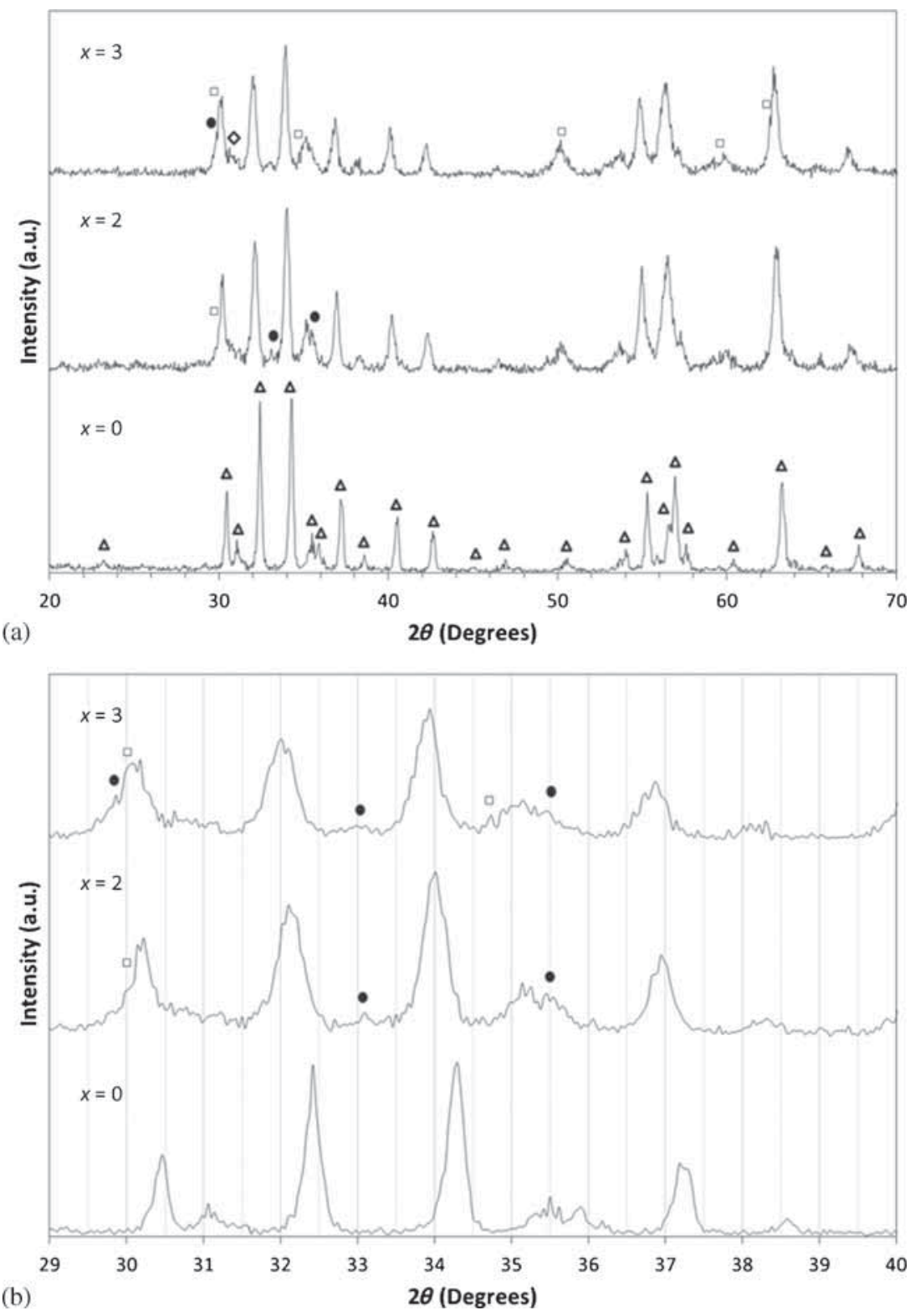

Figure 1. (a) XRD patterns of the samples $x_{0}, x_{2}$ and $x_{3}$ and (b) the same XRD patterns with higher magnification. $\Delta, \mathrm{SrFe}_{12} \mathrm{O}_{19} ; \bullet, \mathrm{Mn}_{\delta} \mathrm{Fe}_{2-\delta} \mathrm{O}_{4} ; \square, \mathrm{SrO}$ and $\diamond, \mathrm{SrZrO}_{3}$. 
the Rietveld method using material analysis using diffraction (MAUD) software [21]. FTIR spectrum was obtained by using a Fourier transform infrared spectrometer (FTIR) model $8400 \mathrm{~S}$. The morphology and microstructure of the nanoparticles were studied by a field emission scanning electron microscope (FESEM) model (MIRA $\backslash$ TESCAN) and transmission electron microscope (TEM) at $200 \mathrm{kV}$ (Philips CM200). Selected area diffraction (SAD) patterns were also taken on TEM. Magnetic properties have been taken out at room temperature at the maximum applied field of $14 \mathrm{kOe}$ by vibrating sample magnetometer (VSM) model MDK. Mössbauer spectra of the samples were recorded using Mössbauer spectrometer (Model CM 1101 Russia) with velocity in the range of -10 to $10 \mathrm{~mm}$ per s under constant acceleration at room temperature. The $\gamma$-rays were provided by ${ }^{57} \mathrm{Co}$ source in Rh matrix. The Mössbauer spectra were analysed by Mossfit software.

\section{Results and discussion}

$\mathrm{X}$-ray diffraction patterns of the samples $x_{0}, x_{2}$ and $x_{3}$ calcined at $800^{\circ} \mathrm{C}$ for $1 \mathrm{~h}$ in air are shown in figure 1 . XRD results of the sample $x_{0}$ show the formation of $\mathrm{SrFe}_{12} \mathrm{O}_{19}$. With addition of $\mathrm{Zr}-\mathrm{Mn}$ dopants, XRD peaks were broadened and $2 \theta$ values shift to lower angels (which is shown in figure $1 \mathrm{~b}$ with higher magnification) due to the differences in ionic radii of the $\mathrm{Zr}$ and $\mathrm{Mn}$ ions with $\mathrm{Fe}$ ions in the structure. XRD results show that $\operatorname{Sr}(\mathrm{Mn}, \mathrm{Zr})_{x} \mathrm{Fe}_{12-x} \mathrm{O}_{19}$ phase is formed with the addition of $\mathrm{Zr}-\mathrm{Mn}$ and also it shows the probability of presence of $\mathrm{SrO}, \mathrm{SrZrO}_{3}$ and $\mathrm{Mn}_{\delta} \mathrm{Fe}_{2-\delta} \mathrm{O}_{4}$ phases along with it. Figure $1 \mathrm{~b}$ shows the position of mentioned phases with higher magnification.

Figure 2 shows the lattice constants ( $a$ and $c$ ) of the samples which were calculated using MAUD software. Rietveld refinement results of the sample $x_{2}$ calcined at $800^{\circ} \mathrm{C}$ for $1 \mathrm{~h}$ are shown in figure 3 . It could be observed that the values of lattice constants increase by increasing $x$ values of the samples. This is due to the larger ionic radii of the substituted

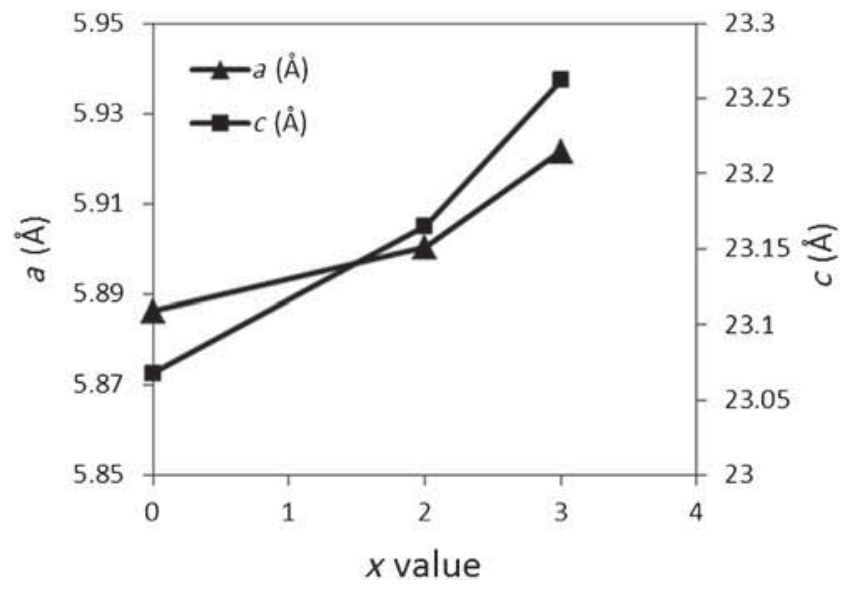

Figure 2. Variations of the lattice constant of $\mathrm{Sr}(\mathrm{Mn}, \mathrm{Zr})_{x} \mathrm{Fe}_{12-x} \mathrm{O}_{19}$ as a function of $x$. ions $\left(r_{\mathrm{Zr}}^{4+}=0.80 \AA\right.$ and $\left.r_{\mathrm{Mn}}^{2+}=0.81 \AA\right)$ in comparison with ionic radius of $\mathrm{Fe}^{3+}(0.64 \AA)$.

FTIR spectroscopy of sample $x_{2}$ is shown in figure 4, which helps to investigate the presence of lateral phases in the substituted samples more precisely. The observed band at around $435 \mathrm{~cm}^{-1}$ is corresponded to asymmetric vibration frequency of $\mathrm{Sr}-\mathrm{O}$ bond [22]. Also the band at about $560 \mathrm{~cm}^{-1}$ is attributed to the tetrahedral metal-oxygen (M-O) sub-lattices of the $\mathrm{MnFe}_{2} \mathrm{O}_{4}$ [23]. The vibration bands are due to the $\mathrm{Zr}$ and $\mathrm{Sr}$ bonds with oxygen atoms expected to exhibit similar energies and bands near each other at approximately $600 \mathrm{~cm}^{-1}$ in the spectrum. A centred broad band at approximately $600 \mathrm{~cm}^{-1}$ is for perovskite structure of $\mathrm{SrZrO}_{3}$ [24]. Therefore, FTIR results prove the presence of $\mathrm{SrZrO}_{3}, \mathrm{SrO}$ and $\mathrm{MnFe}_{2} \mathrm{O}_{4}$ phases.

Figure 5 shows FESEM micrographs of the samples $x_{0}$ and $x_{2}$, which were provided with 'in beam' detector. Figure 5a, $b$ shows FESEM image and its related EDS profile of the sample $x_{0}$. Coarse and highly aggregated particles of strontium hexaferrite could be observed in this picture. Energydispersive X-ray spectroscopy (EDS) spectrum demonstrates the presence of $\mathrm{Sr}, \mathrm{Fe}$ and $\mathrm{O}$ elements in the sample. Figure $5 \mathrm{c}$ shows that the presence of $\mathrm{Zr}-\mathrm{Mn}$ dopants which reduces the Sr-hexaferrite particle size. Also, these ions may

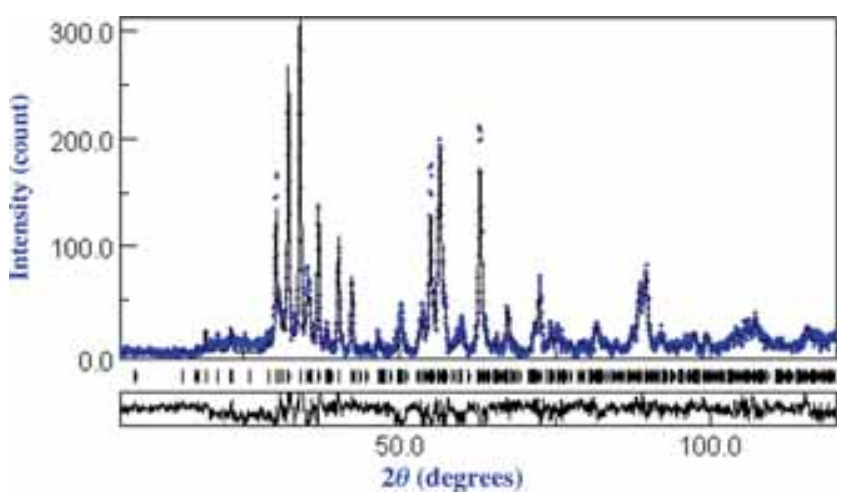

Figure 3. XRD pattern and Rietveld refinement result of sample $x_{2}$.

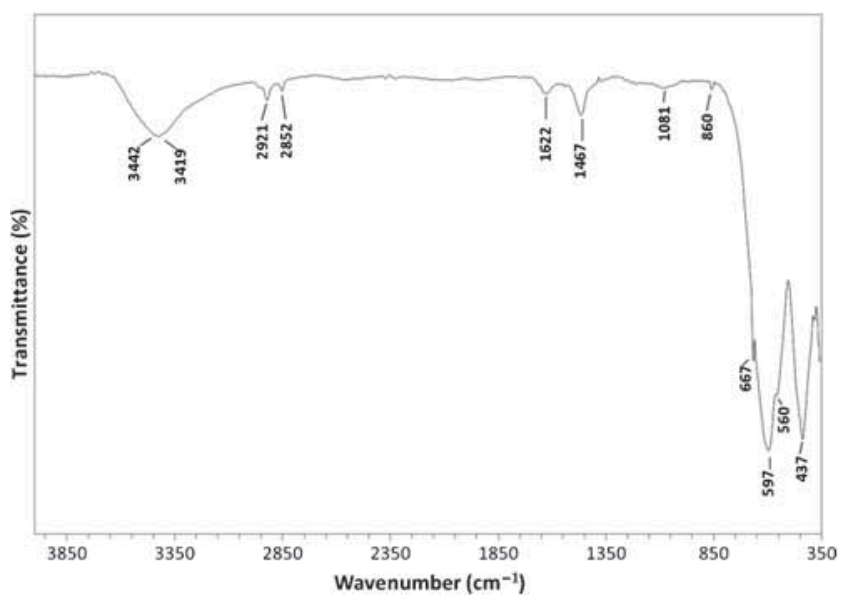

Figure 4. FTIR spectra of sample $x_{2}$. 
play the role of growth inhibitors during the combustion and calcination processes [25].

The presence of two distinct powder morphologies with different brightness levels is observable in figure 5c. This could demonstrate at least two distinct phases which is in consistence with XRD and FTIR results. The mean atomic weight of strontium hexaferrite and $\mathrm{Mn}_{\delta} \mathrm{Fe}_{2-\delta} \mathrm{O}_{4}$ are nearly the same, while mean atomic weight of $\mathrm{SrZrO}_{3}$ and $\mathrm{SrO}$ phases are higher. Therefore, the particles with higher brightness might be recognized as the particles of the two latter phases. EDS spectrum of the bright particles in sample $x_{2}$ shows the presence of $\mathrm{Mn}$ and $\mathrm{Zr}$ in addition to $\mathrm{Sr}, \mathrm{Fe}$ and $\mathrm{O}$ atoms.

Figure 6 represents TEM images of samples $x_{0}$ and $x_{2}$. It could be observed that the particle sizes in both samples are less than $100 \mathrm{~nm}$ and the particles are highly aggregated. This is because of the nature of the combustion process. Small hexagonal shaped particles with nanometric sizes could be observed in these images. Ring patterns which are the characteristic of nano powders [26] are visible in SAD patterns of both samples. Figure $6 \mathrm{~b}$ and $\mathrm{d}$ are the images of the samples with higher magnification that shows crystalline nature of the particles.

The room temperature Mössbauer spectra of samples $x_{0}$, $x_{2}, x_{2.5}$ and $x_{3}$ are shown in figure 7 and the Mössbauer parameters for samples $x_{0}, x_{2}, x_{2.5}$ and $x_{3}$ are presented in table 1 . The spectrum of the sample with $x=0$ is well-fitted by a superposition of five magnetically split spectra indicating the presence of five different crystallographic iron sites with relative area ratios of 2:1:2:6:1 corresponding to the $4 \mathrm{f} 2,2 \mathrm{a}$, $4 \mathrm{f} 1,12 \mathrm{k}$ and $2 \mathrm{~b}$ sites. The analysis of Mössbauer spectrum revealed that the relative magnetic hyperfine interaction $\left(H_{\mathrm{hf}}\right)$ and isomer shift (IS) of sample with $x=0$ respectively are: $H_{\mathrm{hf}}(2 \mathrm{~b})<H_{\mathrm{hf}}(12 \mathrm{k})<H_{\mathrm{hf}}(4 \mathrm{f} 1)<H_{\mathrm{hf}}(2 \mathrm{a})<H_{\mathrm{hf}}(4 \mathrm{f} 2)$ and IS $(4 \mathrm{f} 1)<$ IS $(2 \mathrm{~b})<$ IS $(12 \mathrm{k})<$ IS $(2 \mathrm{a})<$ IS (4f2). A negative large quadrupole splitting is observed for the sextet attributed to $\mathrm{Fe}^{3+}$ ions at trigonal bi-pyramidal (2b) sites which indicates the presence of a large electric field gradient acting on $\mathrm{Fe}^{3+}$ at $2 \mathrm{~b}$ site due to strongly distorted environment of this site [27]. The above assignment is fully in agreement with previous works which is derived based on considerations of both magnetic and crystal structures of $\mathrm{SrFe}_{12} \mathrm{O}_{19}$ [28].
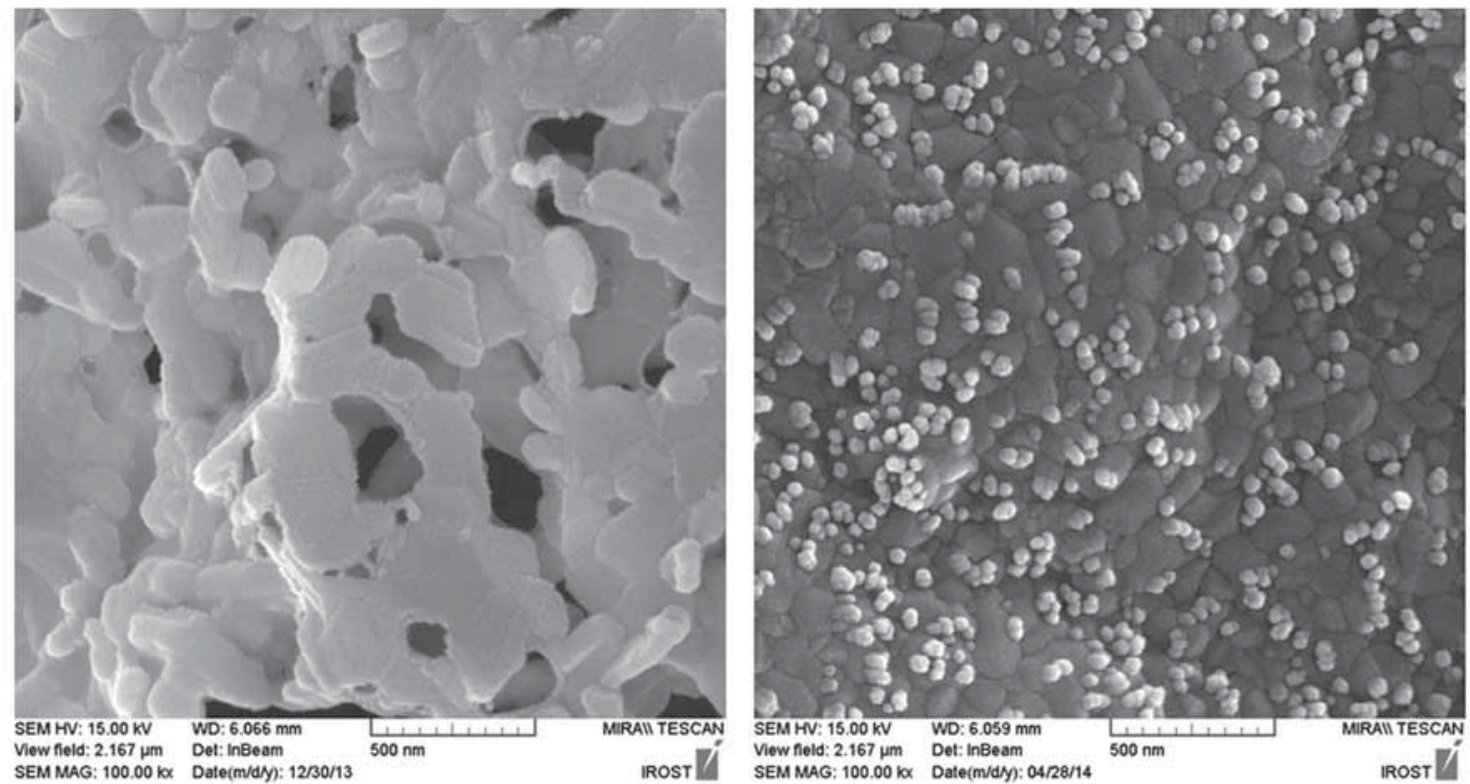

(a)

(c)
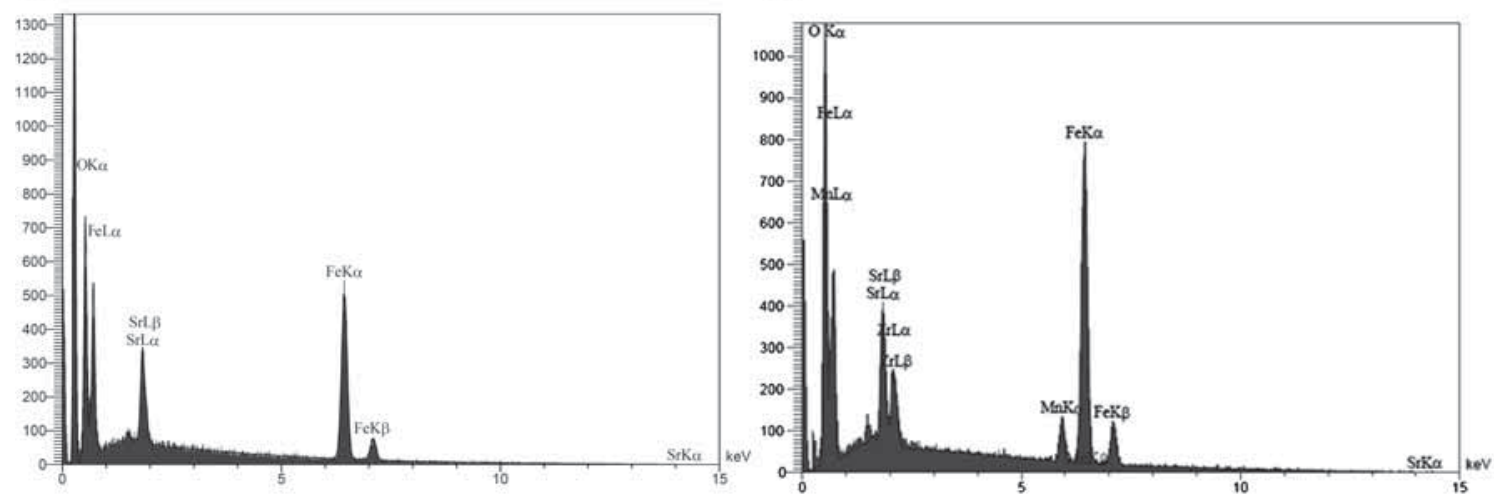

(b)

(d)

Figure 5. FESEM images of samples (a) $x_{0},(\mathbf{b})$ its related EDS analysis, (c) $x_{2}$ and (d) its related EDS analysis. 


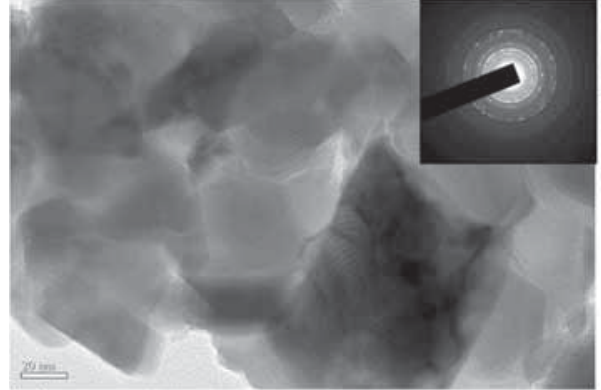

(a)

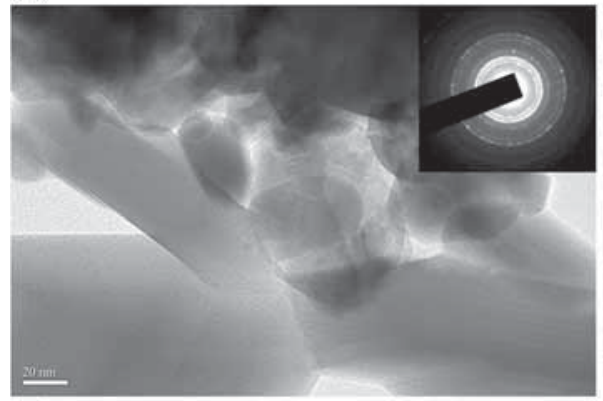

(c)

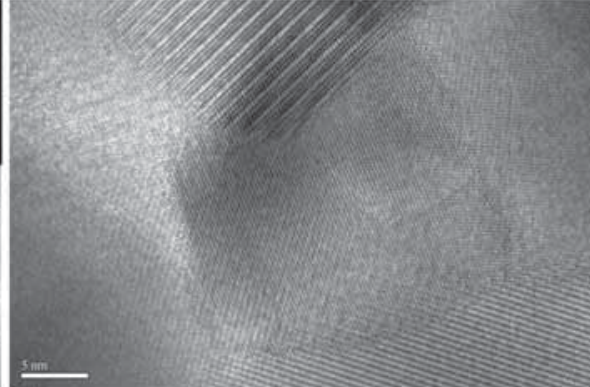

(b)

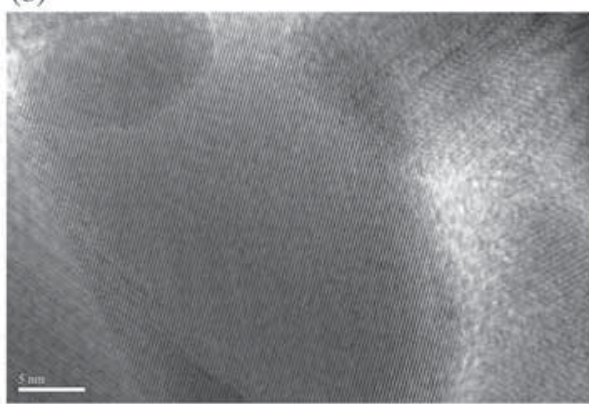

(d)

Figure 6. TEM images of (a) sample $x_{0}$ and its related SAD pattern, (b) sample $x_{0}$ with higher magnification, (c) sample $x_{2}$ and its related SAD pattern and (d) sample $x_{2}$ with higher magnification.

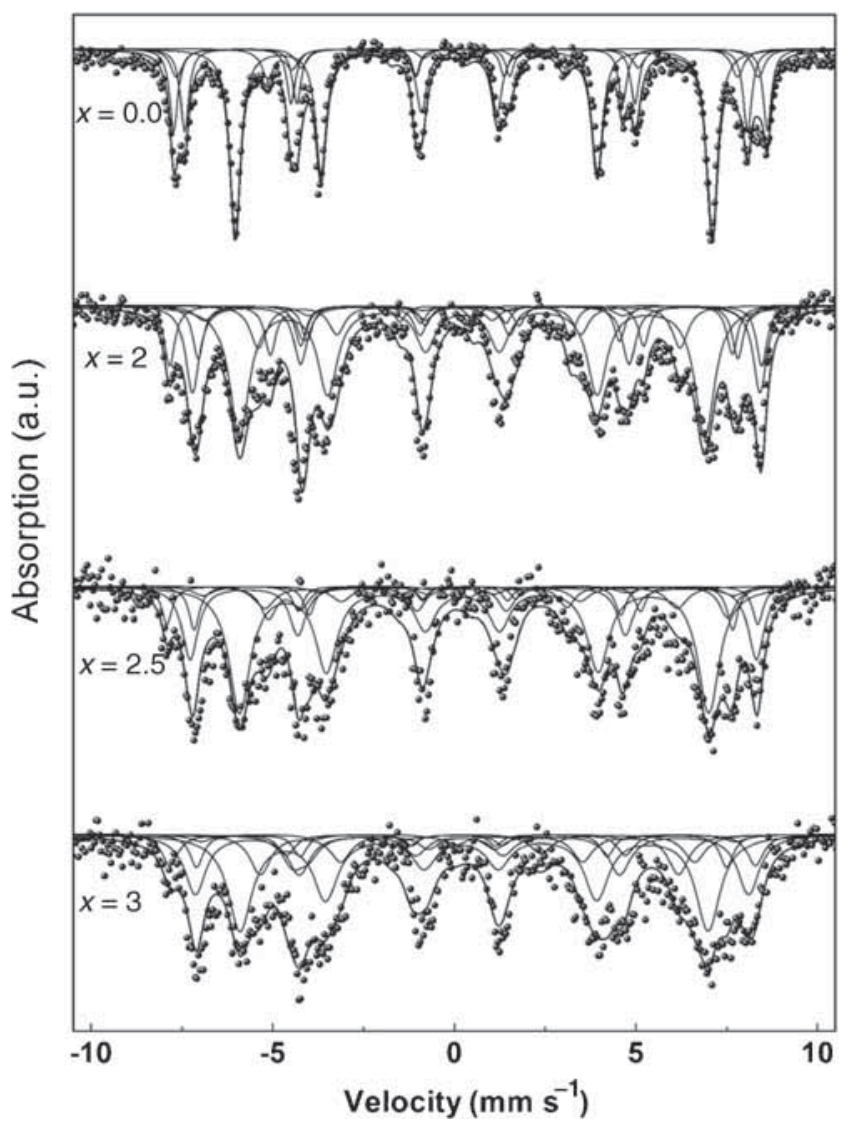

Figure 7. Mössbauer spectra of samples $x_{0}, x_{2}, x_{2.5}$ and $x_{3}$.

Mössbauer spectra of the samples with $x \geq 2$ clearly shows an extra sextet beside of $\mathrm{Sr}(\mathrm{Mn}, \mathrm{Zr})_{x} \mathrm{Fe}_{12-x} \mathrm{O}_{19}$ Lorentzian sextets which is attributed to impurity phase of $\mathrm{Mn}_{\delta} \mathrm{Fe}_{2-\delta} \mathrm{O}_{4}$ that observed in the XRD patterns. The intensity of each sextet is directly proportional to the number of iron ions in each site, so occupancy rate of substitution elements can be estimated. Mössbauer results showed that at low level of substitution, $\mathrm{Zr}^{4+}$ ions prefer to occupy both $4 \mathrm{f} 1$ and $2 \mathrm{~b}$ however, at higher level of substitution, it prefer exclusively $4 \mathrm{f} 1$ site. While the $\mathrm{Mn}^{2+}$ ions distributed approximately equally between $12 \mathrm{k}$ and $2 \mathrm{a}$ sites. The Mössbauer spectra show that the line width increases with the increase of ( $\mathrm{Mn}, \mathrm{Zr}$ ) amount, in fact any changes in environment of iron nuclei could influence a line broadening; hence, the sextets assigned to $12 \mathrm{k}$ and $2 \mathrm{a}$ are expected to be more broadened. This may be explained by considering the crystal structure of $\mathrm{Sr}(\mathrm{Mn}, \mathrm{Zr})_{x} \mathrm{Fe}_{12-x} \mathrm{O}_{19}$ and changes in magnetic interaction. The nearest neighbour of iron ion at $4 \mathrm{f} 1$ site are $12 \mathrm{k}$ and $2 \mathrm{a}$ sites [28,29], so, the substitution of $\mathrm{Fe}^{3+}$ ion by a nonmagnetic $\mathrm{Zr}^{4+}$ ion at $4 \mathrm{f} 1$ site leads to a decrease in exchange interaction and a spin canting at $12 \mathrm{k}$ and $2 \mathrm{a}$ sites [30]. This substitution not only lead to a line broadening, but also it causes the sextet assigned to $12 \mathrm{k}$ site split to $12 \mathrm{k}$ and $12 \mathrm{k}^{\prime},\left(12 \mathrm{k}^{\prime}\right.$ sextet assigned to those iron ions which $4 \mathrm{f} 1$ sites at their vicinity are substituted by $\left.\mathrm{Zr}^{4+}\right)$. The magnetic hyperfine interaction $\left(H_{\mathrm{hf}}\right)$ shows a decrease by increase of $(\mathrm{Mn}, \mathrm{Zr})$ content. The magnetic moment of $\mathrm{Mn}^{2+}$ is $5 \mu_{\mathrm{B}}$, so regardless to the effect of difference in ionic radius of $\mathrm{Fe}^{+3}$ and $\mathrm{Mn}^{2+}$ in superexchange, the drastic change in magnetic properties cannot be attributed to the effect of Mn substitution [9]. In fact, the presence of nonmagnetic $\mathrm{Zr}^{4+}$ cations leads to decrease in exchange interaction especially at $12 \mathrm{k}$ and $2 \mathrm{a}$ sites.

Magnetic properties of different samples were measured using a VSM. The intrinsic coercivity force $\left({ }_{\mathrm{i}} H_{\mathrm{c}}\right)$ and maximum magnetization $\left(M_{\max }\right)$ of the samples are shown in 
Table 1. Mössbauer parameters for samples $x_{0}, x_{2}, x_{2.5}$ and $x_{3}$.

\begin{tabular}{|c|c|c|c|c|c|c|}
\hline $\mathrm{Sr}(\mathrm{Mn}, \mathrm{Zr})_{x} \mathrm{Fe}_{12-x} \mathrm{O}_{19}$ & Sextet & IS $\left(\mathrm{mm} \mathrm{s}^{-1}\right)$ & $\mathrm{QS}\left(\mathrm{mm} \mathrm{s}^{-1}\right)$ & $H_{\mathrm{hf}}(\mathrm{T})$ & $W\left(\mathrm{~mm} \mathrm{~s}^{-1}\right)$ & Area $(\%)$ \\
\hline \multirow[t]{5}{*}{$x=0.0$} & $12 \mathrm{k}$ & 0.34 & -0.34 & 40.79 & 0.35 & 49.87 \\
\hline & $4 f_{1}$ & 0.23 & -0.17 & 48.14 & 0.26 & 16.62 \\
\hline & $4 f_{2}$ & 0.33 & -0.20 & 50.75 & 0.26 & 16.52 \\
\hline & $2 \mathrm{a}$ & 0.39 & 0.06 & 49.75 & 0.4 & 8.51 \\
\hline & $2 b$ & 0.30 & -2.04 & 40.21 & 0.4 & 8.48 \\
\hline \multirow[t]{7}{*}{$x=2$} & $12 \mathrm{k}$ & 0.35 & -0.26 & 39.79 & 0.64 & 41.41 \\
\hline & $12 \mathrm{k}^{\prime}$ & 0.26 & -0.28 & 36.04 & 0.53 & 8.54 \\
\hline & $4 \mathrm{f}_{1}$ & 0.31 & -0.13 & 46.16 & 0.35 & 8.89 \\
\hline & $4 f_{2}$ & 0.44 & -0.31 & 48.53 & 0.44 & 18.17 \\
\hline & $2 \mathrm{a}$ & 0.44 & -0.25 & 46.36 & 0.67 & 4.7 \\
\hline & $2 b$ & 0.40 & -1.78 & 39.51 & 0.35 & 8.18 \\
\hline & $\mathrm{Mn}_{\delta} \mathrm{Fe}_{2-\delta} \mathrm{O}_{4}$ & 0.40 & 0.18 & 50.63 & 0.35 & 10.12 \\
\hline \multirow[t]{7}{*}{$x=2.5$} & $12 \mathrm{k}$ & 0.38 & -0.32 & 40.11 & 0.71 & 41.45 \\
\hline & $12 \mathrm{k}^{\prime}$ & 0.31 & -0.28 & 35.27 & 0.66 & 11.54 \\
\hline & $4 f_{1}$ & 0.27 & 0.04 & 46.05 & 0.35 & 7.96 \\
\hline & $4 f_{2}$ & 0.36 & -0.31 & 48.41 & 0.53 & 19.93 \\
\hline & $2 \mathrm{a}$ & 0.45 & 0.13 & 45.37 & 0.71 & 3.46 \\
\hline & $2 b$ & 0.31 & -1.7 & 39.28 & 0.53 & 8.69 \\
\hline & $\mathrm{Mn}_{\delta} \mathrm{Fe}_{2-\delta} \mathrm{O}_{4}$ & 0.31 & 0.2 & 50.51 & 0.35 & 6.96 \\
\hline \multirow{7}{*}{$x=3$} & $12 \mathrm{k}$ & 0.36 & -0.35 & 40.02 & 0.80 & 37.81 \\
\hline & $12 \mathrm{k}^{\prime}$ & 0.30 & -0.21 & 35.75 & 0.66 & 13.18 \\
\hline & $4 f_{1}$ & 0.09 & -0.22 & 45.33 & 0.44 & 7.26 \\
\hline & $4 f_{2}$ & 0.31 & -0.34 & 47.31 & 0.71 & 21.08 \\
\hline & $2 \mathrm{a}$ & 0.40 & 0.04 & 45.69 & 0.75 & 2.69 \\
\hline & $2 b$ & 0.13 & -2 & 34.37 & 0.71 & 9.71 \\
\hline & $\mathrm{Mn}_{\delta} \mathrm{Fe}_{2-\delta} \mathrm{O}_{4}$ & 0.14 & -0.18 & 50.05 & 0.53 & 8.27 \\
\hline
\end{tabular}

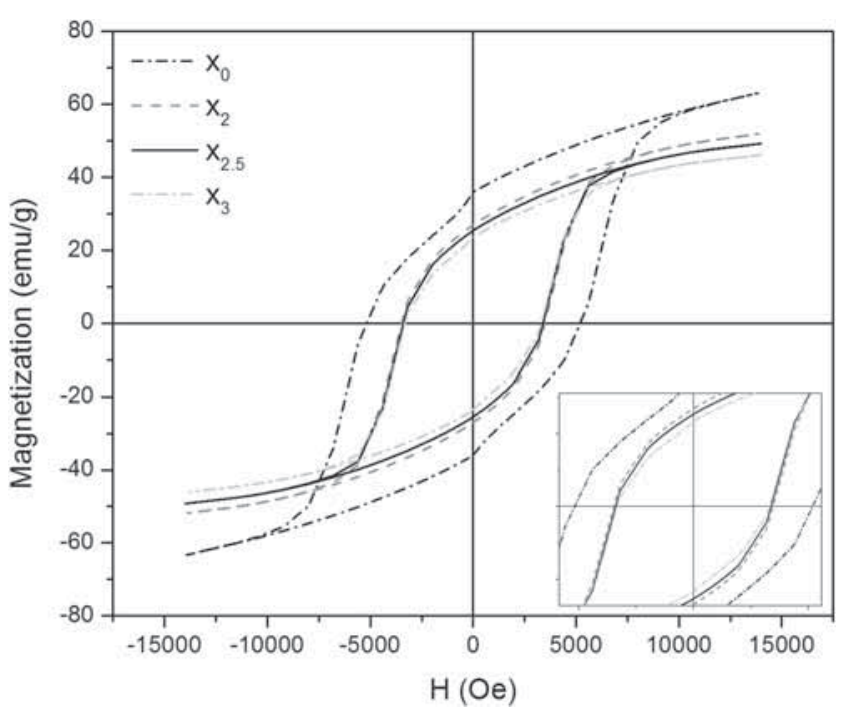

Figure 8. Hysteresis loops of samples (a) $x_{0}$, (b) $x_{2}$, (c) $x_{2.5}$ and (d) $x_{3}$.

figure 8 and table 2 . It can be seen that ${ }_{\mathrm{i}} H_{\mathrm{c}}$ and $M_{\max }$ values were decreased with increasing $x$ value from 5.18 to $3.28 \mathrm{kOe}$ and from 63.34 to $46.15 \mathrm{emu} \mathrm{g}^{-1}$, respectively. This reduction in $M_{\max }$ and ${ }_{\mathrm{i}} H_{\mathrm{c}}$ values is for the sake of embedment of $\mathrm{Zr}$ and $\mathrm{Mn}$ cations in strontium hexaferrite structure.
Table 2. The intrinsic coercivity $\left({ }_{\mathrm{i}} H_{\mathrm{c}}\right)$ and maximum magnetization $\left(M_{\max }\right)$ values of the samples $x_{0}, x_{2}, x_{2.5}$ and $x_{3}$.

\begin{tabular}{lcc}
\hline Sample code $(x)$ & $M_{\max }\left(\mathrm{emu} \mathrm{g}^{-1}\right)$ & ${ }_{\mathrm{i}} H_{\mathrm{c}}(\mathrm{Oe})$ \\
\hline$x_{0}$ & 63.34 & 5177.24 \\
$x_{2}$ & 52 & 3475.94 \\
$x_{2.5}$ & 49.26 & 3395.76 \\
$x_{3}$ & 46.15 & 3282.46 \\
\hline
\end{tabular}

The total magnetic moments of $\mathrm{SrFe}_{12} \mathrm{O}_{19}$ unit cell is equal to $20 \mu_{\mathrm{B}}$. It was reported that $\mathrm{Mn}^{2+}$ ions occupy $12 \mathrm{k}$ and 2a sites [31], which is in consistence with our Mössbauer studies, while our calculations showed that $\mathrm{Zr}^{4+}$ ions substituted at $4 \mathrm{f} 1$ and $2 \mathrm{~b}$ sites and they preferentially to occupy $4 \mathrm{f} 1$ site rather than $2 \mathrm{~b}$ site. The electrons in $12 \mathrm{k}, 2 \mathrm{a}$ and $2 \mathrm{~b}$ sites have spin up direction, while in $4 \mathrm{f}_{1}$ and $4 \mathrm{f}_{2}$, they are spin down [32]. The replacement of $\mathrm{Fe}^{3+}$ by $\mathrm{Mn}^{2+}$ ions mainly do not change the maximum magnetization since both $\mathrm{Fe}^{3+}$ and $\mathrm{Mn}^{2+}$ have five unpaired electrons in their outermost shell and both have the magnetic moment of $5 \mu_{B}$ [33]. Thus, reduction of the saturation magnetization is due to the replacement of $\mathrm{Fe}^{3+}$ by $\mathrm{Zr}^{4+}$ ions at $4 \mathrm{f}_{1}$ sites. It was reported that when a nonmagnetic $\mathrm{Zr}^{4+}$ cation $(x \leq 0.4)$ replaces the $\mathrm{Fe}^{3+}$ at $4 \mathrm{f}_{1}$ sites (with down spin), then the total number of electrons in upward spin has been increased which 


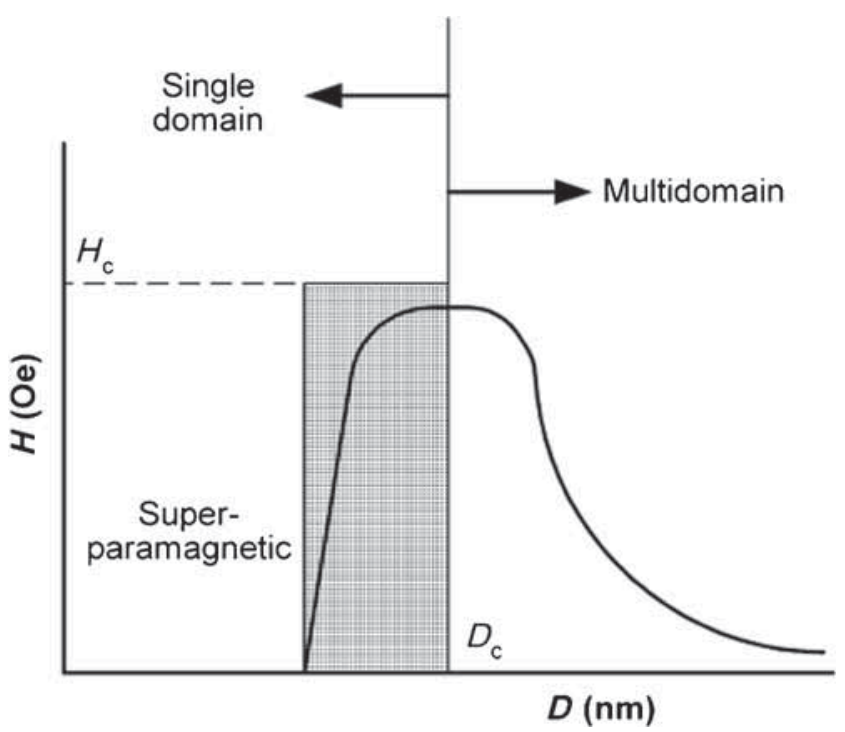

Figure 9. Schematic illustration of ${ }_{\mathrm{i}} H_{\mathrm{c}}$ values variations with the average particle diameter $(D)$ [33].

result in saturation magnetization increment. However, when $x$ values are higher than $x=0.4$, the amount of $\mathrm{Fe}^{3+}$ replaced by nonmagnetic $\mathrm{Zr}^{4+}$ ions increase too much which leads to weakening of all the exchange interactions between $4 \mathrm{f}_{1}-12 \mathrm{k}$ and $4 \mathrm{f}_{1}-2 \mathrm{a}$; therefore, the maximum magnetization decreases. The coercivity force decreases with increment in $\mathrm{Zr}-\mathrm{Mn}$ content due to decrement in magnetocrystalline anisotropy because the occupation of $\mathrm{Mn}$ ions at $12 \mathrm{k}$ and $2 \mathrm{a}$ sites have negative influence on anisotropy [33]. Also, particle size might affect ${ }_{\mathrm{i}} H_{\mathrm{c}}$ value. Figure 9 shows the changes in ${ }_{\mathrm{i}} H_{\mathrm{c}}$ values with particle size [34]. When the particle size is smaller than a critical size $(650 \mathrm{~nm})$ [1], the particles have been located to single domain region. In this case, domain wall motion mechanism was the dominated mechanism of magnetization vector rotation. So, when the particle size decreases, the grain boundaries were an obstacle to the movement of the domain walls. As a result, the magnetic coercivity has been increased. On the other hand, if the particle size becomes less than a critical particle size $(40-60 \mathrm{~nm})$, the particles start to approach the super paramagnetic behaviour [35-37]. As mentioned previously, figure 5 demonstrates that addition of $\mathrm{Zr}^{4+}$ and $\mathrm{Mn}^{2+}$ ions causes particle size refinement. Therefore, some particles begin to approach the super paramagnetic behaviour and would decrease ${ }_{\mathrm{i}} H_{\mathrm{c}}$ value.

\section{Conclusion}

$\mathrm{Zr}-\mathrm{Mn}$ substituted strontium hexaferrite $\mathrm{Sr}(\mathrm{Zr}, \mathrm{Mn})_{x} \mathrm{Fe}_{12-2 x} \mathrm{O}_{19}$ $(x=0,2,2.5,3)$ nano-sized powders were synthesized by sol-gel auto-combustion route using subsequent heat treatment. XRD results have been revealed that the main phase is $\mathrm{Sr}(\mathrm{Zr}, \mathrm{Mn})_{x} \mathrm{Fe}_{12-2 x} \mathrm{O}_{19}$. XRD and FTIR results confirm the presence of $\mathrm{SrO}, \mathrm{SrZrO}_{3}$ and $\mathrm{Mn}_{\delta} \mathrm{Fe}_{2-\delta} \mathrm{O}_{4}$ lateral phases. FESEM micrographs represent refinement of particle size and the presence of two distinct powder morphologies with different brightness levels with substitutions, which approves existence of lateral phases in the substituted samples. TEM micrographs show nanometric particles with sizes smaller than $100 \mathrm{~nm}$ with high crystallinity. Magnetic measurements exhibit that with increase in the amount of dopants, ${ }_{\mathrm{i}} H_{\mathrm{c}}$ and $M_{\max }$ values decrease from 5593.60 to $3282.46 \mathrm{Oe}$ and from 62.60 to $46.15 \mathrm{emu} \mathrm{g}^{-1}$, respectively. Mössbauer spectra show that the presence of nonmagnetic $\mathrm{Zr}^{4+}$ cations at $4 \mathrm{f} 1,12 \mathrm{k}$ and $2 \mathrm{a}$ leads to decrease in exchange interaction especially at $12 \mathrm{k}$ and $2 \mathrm{a}$ sites; which is the main reason for drastic changes in magnetic properties of the samples.

\section{References}

[1] de Araújo J H, Soares J M, Ginani M F, Machado F L A and da Cunha J B M 2013 J. Magn. Magn. Mater. 343203

[2] Wang Y, Li Q, Zhang C and Li B 2009 J. Magn. Magn. Mater. 3213368

[3] Nga T T V, Duong N P, Loan T T and Hien T D 2014 J. Alloys Compd. 610630

[4] Masoudpanah S M and Seyyed Ebrahimi S A 2013 J. Magn. Magn. Mater. 342128

[5] Ghasemi A 2013 J. Magn. Magn. Mater. 330163

[6] Ur Rashid A, Southern P, Darr J A, Awan S and Manzoor S 2013 J. Magn. Magn. Mater. 344134

[7] Lee S W, An S Y, Shim I and Kim C S 2005 J. Magn. Magn. Mater. 290-291 231

[8] Kuo H M, Hsui T, Tuo Y S and Yuan C L 2012 J. Mater. Sci. 472264

[9] Iqbal M J, Ashiq M N, Gomez P H, Munoz J M and Cabrera C T 2010 J. Alloys Compd. $\mathbf{5 0 0} 113$

[10] Kumar N, Kumar A, Jha R, Dogra A, Pasricha R, Kotnala $\mathrm{R}$ K et al 2010 J. Supercond. Nov. Magn. 23423

[11] Jacobo S E, Blesa M A, Domingo-Pascual C and RodpigguezClemente R 1997 J. Mater. Sci. 321025

[12] Xia A, Zuo C, Chen L, Jin C and Lv Y 2013 J. Magn. Magn. Mater. 332186

[13] Surig C, Hempel K A and Bonnenborg D 1994 J. IEEE Trans. Magn. 304092

[14] Alamolhoda S, Seyyed Ebrahimi S A and Badiei A 2006 Phys. Met. Metallography 102 S71

[15] Sivakumar P, Ramesh R, Ramanand A, Ponnusamy S and Muthamizhchelvan C 2012 J. Mater. Sci.: Mater. Electron. 23 1041

[16] Sharbatia A, Choopanib S, Azarc A M and Senna M 2010 Solid State Commun. 1502218

[17] Davoodi A and Hashemi B 2011 J. Alloys Compd. 5095893

[18] Fang Q Q, Bao H W, Fang D M, Wang J Z and Li X G 2004 J. Magn. Magn. Mater. 278122

[19] Iqbal M J, Ashiq M N, Gomez P H, Munoz J M and Cabrera C T 2010 J. Alloys Compd. $\mathbf{5 0 0} 113$

[20] Ghasemi A and Morisako A 2008 J. Alloys Compd. 456485

[21] Rietveld H M 1969 J. Appl. Cryst. 265

[22] Sultana Rafiuddin S, Zain Khan M, Umar K, Ahmed A S and Shahadat M 2015 J. Mol. Struct. 1098393 
[23] Aslibeiki B and Kameli P 2015 J. Magn. Magn. Mater. 385 308

[24] de Oliveira Lima J R, Abdul Ghani Y, da Silva R B, Marcos F Batista C, Binib R A et al 2012 Appl. Catal. A Gen. 445-446 76

[25] Iqbal M J and Ashiq M N 2007 Scripta Mater. 56145

[26] Mula S, Mondal K, Ghosh S and Pabi S K 2010 Mater. Sci. Eng. A 5273757

[27] Rao P M, Rard G and Grandjea P 1979 Phys. Status Solidi 54529

[28] Fu H, Zhai H R, Zhang Y C, Gu B X and Li Y J 1986 J. Magn. Magn. Mater. 54-57 905

[29] Collomb A, Lambert Andron B, Boucherle J X and Samaras D 1986 Phys. Status Solidi 96385
[30] Rane M V, Bahadur D, Nigam A K and Srivastava C M 1999 J. Magn. Magn. Mater. 192288

[31] Iqbal M J, Ashiq M N and Jndez-Gmezc P H 2010 J. Alloys Compd. $\mathbf{5 0 0} 113$

[32] Mathew D S and Juang R 2007 Chem. Eng. J. 12951

[33] Zi Z F, Sun Y P, Zhu X B, Yang Z R, Dai J M and Song W H 2008 J. Magn. Magn. Mater. 3202746

[34] Pullar R C 2012 Prog. Mater. Sci. 571191

[35] Evans B J, Grandjen F, Lilot A P, Vogel R H and Gerard A 1987 J. Magn. Magn. Mater. 67123

[36] Li Z W, Ong C K, Yang Z, Wei F L, Zhou X Z, Zhao J H and Morrish A H 2000 Phys. Rev. B 626530

[37] Dionne G F 1970 J. Appl. Phys. 414874 